\title{
The Independent and Combined Effects of Aerobic Exercise Training and Eugenol Consumption on Cardiac Acetylcholinesterase (AChE) in Chlorpyrifos Poisoned Rats
}

\author{
Fatemeh Soltani-Moez ${ }^{1}$ and Saleh Rahmati-Ahmadabad (iD) ${ }^{2, *}$ \\ ${ }^{1}$ Department of Exercise Physiology, Central Tehran Branch, Islamic Azad University, Tehran, Iran \\ ${ }^{2}$ Department of Physical Education, Pardis Branch, Islamic Azad University, Pardis, Iran \\ "Corresponding author: Department of Physical Education, Pardis Branch, Islamic Azad University, Pardis, Iran. Email: salehrahmati@pardisiau.ac.ir
}

Received 2020 December 22; Revised 2021 March 14; Accepted 2021 March 24.

\begin{abstract}
Chlorpyrifos is an insecticide that can induce acute and chronic toxicity against the heart by affecting acetylcholinesterase (AChE or acetylhydrolase). The present study investigated the independent and combined effects of aerobic training and eugenol consumption on heart AChE in chlorpyrifos-poisoned rats. A total of 56 healthy Wistar male rats were randomly and equally assigned to several groups receiving various treatments: saline healthy-control, corn oil healthy-sham, dimethylsulfoxide (DMSO) healthy-sham, saline-toxic control, saline-toxic-training, eugenol-toxic control, and eugenol-toxic-training. The study groups with toxic labels initially received chlorpyrifos injections for six weeks. Then they received other treatments according to their labels (i.e., moderateintensity aerobic training five sessions/week for six weeks and/or $250 \mathrm{mg} / \mathrm{kg}$ eugenol). Twenty-four hours after the last treatment, rats were anesthetized, and their left ventricles were collected, frozen, and sent to the laboratory. The data were analyzed using one-way and two-way analysis of variance (ANOVA). A P-value $<0.05$ was considered as a statistically significant difference between groups. The results showed that chlorpyrifos treatment decreased cardiac AChE. Besides, aerobic training and eugenol supplementation independently increased cardiac AChE in chlorpyrifos treated rats. The combination of aerobic training and eugenol consumption had no extra effect on the cardiac AChE level compared with each treatment alone in the rats exposed to chlorpyrifos. In conclusion, aerobic training and eugenol treatment had a positive effect on cardiac AChE in the rats poisoned with chlorpyrifos. So, these interventions may be beneficial to deter the chronic effects of chlorpyrifos on the heart. Future studies should also take into account several other factors related to cardiac health.
\end{abstract}

Keywords: Acetylcholinesterase (AChE), Acetylhydrolase, Insecticide, Organophosphorus, Toxicity

\section{Background}

Nowadays, the widespread use of organophosphorus insecticides has resulted in the accumulation of toxic materials, environmental problems, and acute and chronic poisoning (1). Chlorps, as organophosphorus compounds, are usually used as agricultural pests, beside their sterilization and industrial applications. Like other organophosphates, chlorpyrifos produces toxic effects mainly by inhibiting acetylcholinesterase (AChE or acetylhydrolase) activity (2).

AChE is a cholinesterase enzyme in the body, which catalyzes the breakdown of acetylcholine and some other choline esters. Previous research showed that elevated levels of acetylcholine (Ach) in the rats treated with a cholinesterase inhibitor could increase heart vagal control and consequently decrease heart failure and ventricular dysfunction (3). In another study on patients with heart failure, it was shown that short-term administration of a cholinesterase inhibitor decreased ventricular arrhythmias and increased heart rate variabilities (4). On the other hand, the synaptic accumulation of ACh following AChE inhibition triggered prolonged stimulation of cholinergic receptors and cardiac problems such as bradycardia, transitory discontinuation of heartbeats (vagal escape) via the sinus effect, decreased atrioventricular conduction, and weakened atrium contractions $(5,6)$.

Several studies have examined the protective effects of aerobic exercise and eugenol (an aromatic oil extracted from cloves) consumption on the heart (7-9); however, most studies have focused on the brain and neglected the 
heart. Previous studies showed that aerobic exercise and eugenol supplementation had positive effects on the AChE level (10-12).

Eugenol has been noted to act as a cytoprotective agent against $\mathrm{As}_{2} \mathrm{O}_{3}$-induced cardiotoxicity (13). On the one hand, there is inadequate research on the effects of aerobic exercise and eugenol consumption on cardiac AChE in chlorpyrifos-poisoned rats; and on the other hand, some interventions may have synergic effects when they are administered together.

\section{Objectives}

So, we here aimed to assess the combined effects of aerobic exercise and eugenol supplementation on the cardiac AChE level in the rats treated with chlorpyrifos.

\section{Methods}

\subsection{Ethical Considerations and Animal Housing Condition}

The present study was based on a MSc thesis registered in Islamic Azad University (Central Tehran Branch, Iran), and it was approved by the university's Ethics Committee (no.: 1012911712337521398162268642). Animal experiments complied with the ARRIVE guideline. This study was conducted according to the National Institutes of Health (NIH) publication, and all ethical principles regarding laboratory animals were considered. Rats were kept in standard animal houses (12 hours of light and 12 hours of darkness, $23^{\circ} \mathrm{C} \pm 3{ }^{\circ} \mathrm{C}$ temperature, and approximately $50 \%$ humidity). The animals were kept in standard cages that their floors were covered with wooden foil and had free access to standard food and water.

\subsection{Design}

Fifty-six healthy Wistar male rats (eight weeks old, 180 - $220 \mathrm{~g}$ weight) were randomly and equally assigned to seven different groups, including saline-healthy-control, corn oil-healthy-sham, dimethylsulfoxide (DMSO)-healthysham, saline-chlorpyrifos-control, saline-chlorpyrifostraining, eugenol-chlorpyrifos-control, and eugenolchlorpyrifos-training. In the groups receiving chlorpyrifos, the animals were treated with chlorpyrifos for six weeks. Then they received other interventions based on their group assignments for additional six weeks. At the end of experiments, all the interventions (i.e., exercise, chlorpyrifos exposition, and eugenol supplementation) were discontinued for 24 hours to eliminate their acute effects. Next, the rats were anesthetized with ketamine and xylazine (injected intraperitoneally, 30 - $50 \mathrm{mg} / \mathrm{kg}$ body weight ketamine and 3 - $5 \mathrm{mg} / \mathrm{kg}$ body weight xylazine). The left heart ventricle was removed, washed by saline, cut into three slices, which were immediately frozen in liquid nitrogen. All the samples were stored at $-80^{\circ} \mathrm{C}$ for further analysis. The level of AChE in the left ventricle was measured using a previously described method (14).

\subsection{Inducing Toxicity}

Chlorpyrifos $\left(\mathrm{C}_{9} \mathrm{H}_{11} \mathrm{Cl}_{3} \mathrm{NO}_{3} \mathrm{PS}\right)$ was purchased from Sigma-Aldrich (CAS no.: 2921-88-2, the USA). Chlorpyrifos was first dissolved in DMSO and subsequently diluted with $0.9 \%$ saline in order to avoid DMSO concentration exceeding the $0.01 \%$ v/v final concentration. Finally, DMSOdissolved chlorpyrifos was intraperitoneally injected to rats $(3.0 \mathrm{mg} / \mathrm{kg}$ ) for six weeks (five days/week). The rats in the DMSO-toxic-sham group received an equal volume of DMSO diluted in $0.9 \%$ saline at the same time and duration of chlorpyrifos injection.

\subsection{Eugenol Supplementation}

The animals were fed with eugenol dissolved in corn oil ( $250 \mathrm{mg} / \mathrm{kg}$ body weight, five days a week for six weeks) by gavage (15). Corn oil-toxic-sham group received $10 \mathrm{mg} / \mathrm{kg}$ of corn oil at the same time and duration of eugenol supplementation.

\subsection{Exercise Protocol}

The rats in the exercise groups were orientated with motorized rodent treadmill for two weeks (nine $\mathrm{m} / \mathrm{min}$, and $10 \mathrm{~min} /$ day). After a 2-week of familiarity period, the rats performed four-week running on a treadmill by observing the overload principle $(20 \mathrm{~m} / \mathrm{min}, 26 \mathrm{~min} /$ day, five days/week). They also had 5-min warming-up and 5-min cooling-down before and after each session, respectively.

\subsection{Statistical Analysis}

The results of the Shapiro-Wilk test showed that the data had a normal distribution. The Levene's test confirmed the equality of variances. All results were expressed as means \pm standard deviations (SD). One-way analysis of variance (ANOVA) was used to assess between-group differences. Two-way ANOVA was used to determine the effects of training, eugenol supplementation, and training + eugenol supplementation. Between-group effects were 
determined by a suitable post-hoc test. In addition, the effect size (partial $\eta^{2}$ ) was reported to emphasize the size of the difference rather than the confounding impact of the sample size. All statistical analyses were performed in SPSS software (version 22), considering a significance level of $P$ $>0.05$.

\section{Results}

The results of one-way ANOVA showed that there were significant differences between healthy-control, healthysham, and toxic-control groups comparing cardiac AChE levels $\left(\mathrm{F}=15.04, \mathrm{P}=0.001\right.$; partial $\eta^{2}=0.84$ ) (Figure 1 ). The rats treated with chlorpyrifos showed significant reduction in the cardiac AChE level compared to the animals in the saline-healthy-control $(\mathrm{P}=0.001)$, corn oilhealthy-sham ( $\mathrm{P}=0.002)$, and DMSO-healthy-sham ( $\mathrm{P}=$ 0.001) groups. Differences between other groups were not statistically significant (Figure 1).

The results of two-way ANOVA showed that the exercise program independently increased cardiac AChE in chlorpyrifos-poisoned rats compared to non-trained animals $\left(\mathrm{F}=14.01, \mathrm{P}=0.006\right.$; partial $\eta^{2}=0.63$ ) (Figure 2). Additionally, eugenol consumption independently increased cardiac AChE in chlorpyrifos-poisoned rats compared to the groups that received saline $(\mathrm{F}=11.88, \mathrm{P}=0.009$; partial $\eta^{2}=0.59$ ) (Figure 2). However, the combination of exercise and eugenol consumption showed no synergic effects on the cardiac AChE level in chlorpyrifos-poisoned rats when compared to each intervention alone $(\mathrm{F}=3.60, \mathrm{P}=0.09$; partial $\eta^{2}=0.31$ ) (Figure 2).

\section{Discussion}

The results of the present study showed that chlorpyrifos-induced toxicity significantly decreased cardiac AChE. In addition, six weeks of either aerobic exercise or eugenol supplementation alone improved the cardiac AChE level in the rats treated with chlorpyrifos.

In normal conditions, exercise and eugenol consumption could decrease AChE and consequently increase ACh, improving neuromuscular function and other related factors (10-12). Experimental/clinical studies suggested that AChE inhibitors improved autonomic and cardiac function. These cardioprotective effects are mediated via several mechanisms such as augmenting the beneficial effects of ACh on arrhythmia and modulating apoptosis, oxidative stress, inflammatory factors, etc. (16), protecting against heart failure. On the other hand, several studies showed that dramatic falls in AChE levels could lead to detrimental effects (17). Acetylcholine molecules that do not immediately bind to a receptor or those released via receptor-mediated reactions are rapidly hydrolyzed (in less than one msec) by AChE. Almost fifty percent of released ACh is hydrolyzed into choline and acetate before binding to the receptor (18-24). Choline is taken up by nerves' terminals and reused for ACh synthesis. Thus, large decreases in AChE activity could be detrimental. Particularly, ACh accumulation in the synaptic cleft during intense synaptic activity suppresses the generating of muscles' action potentials (17). It has been shown that the lack of AChE results in mild phenotypic abnormalities and low muscle weight and reduces the cross-sectional area of myofibers and the absolute maximal isometric force (19-22). In addition, AChE deficiency has been associated with muscle weakness (23) and neuromuscular junction dysfunction (24) in humans.

Another study indicated that AChE deficiency could lead to muscle dysfunction (25). In the present research, exposition to chlorpyrifos remarkably decreased cardiac AChE in rats, which was reversed by exercise and eugenol consumption, showing the protective effects of these interventions against chlorpyrifos-induced cardiac toxicity. To the best of our knowledge, no study has yet investigated the effects of exercise and eugenol supplementation on the chlorpyrifos-induced reduction of cardiac AChE. However, some studies have examined the effects of high intensity/fatigue exercises on this enzyme $(26,27)$. For example, Wen et al. (26) evaluated the effects of exercise-induced fatigue on the expression and activity of AChE. Their results showed that the expression of gastrocnemius neuromuscular junctions and AChE activity were temporarily reduced by exercise-induced fatigue and then increased over 24 hours (21). In another report, eugenol was shown to be a beneficial agent against $\mathrm{As}_{2} \mathrm{O}_{3}$-induced cardiotoxicity (13).

The results of the present study showed that aerobic exercise and eugenol supplementation, either alone or in combination with each other, mitigated the adverse effects of chlorpyrifos on cardiac AChE activity, but not to normal levels. It is obvious that these interventions were not sufficient to fully reverse the high-dose toxic effects of chlorpyrifos, which indicates the need for complementary medications. This study demonstrated that exercise and eugenol consumption had positive effects on cardiac AChE in a toxic environment. So, these interventions may be considered for reversing the chronic effects of chlorpyrifos on 


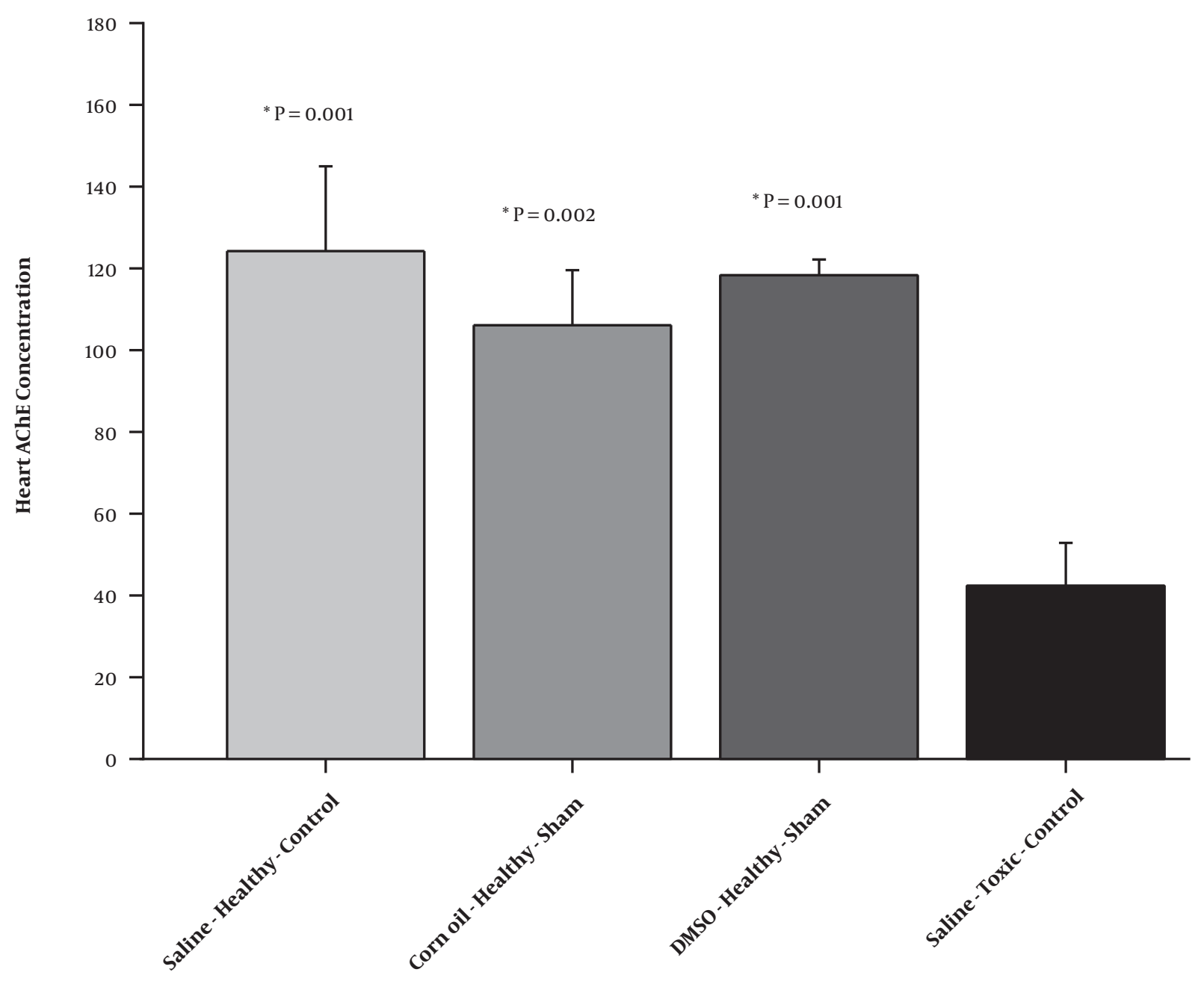

Figure 1. Cardiac acetylcholinesterase (AChE) (ng/mL) in saline-healthy-control, corn oil-healthy-sham, DMSO-healthy-sham, and saline-chlorpyrifos-control groups. There were eight rats in each group. The data were expressed as means \pm standard deviation (SD) and analyzed using one-way ANOVA. *, A significant decrease vs. the salinechlorpyrifos-control group.

the heart. As a limitation of this study, we evaluated only a few factors associated with cardiac function. Future studies should take into account several other factors related to the heart's health, such as apoptosis, oxidative stress, and inflammatory mediators.

\subsection{Conclusions}

The present study suggests aerobic training and eugenol supplementation as strategies to protect cardiac AChE against toxic agents such as chlorpyrifos. The combination of aerobic training and eugenol consumption had no extra effects on cardiac AChE in chlorpyrifos-treated rats compared with each intervention alone. These interventions could be considered as therapeutic modalities to protect the heart against the chronic effects of chlorpyrifos. Future studies should focus on several other factors related to cardiac health.

\section{Acknowledgments}

The authors would like to express their heartiest thanks to MAA PhD for helpful comments.

\section{Footnotes}

Authors' Contribution: The present study was the result of a MSc thesis. SRA (supervisor) designed the study. FSM (MSc. student) collected the materials, performed the 


\section{Training Groups vs Control Groups, $\mathrm{P}=0.006$}

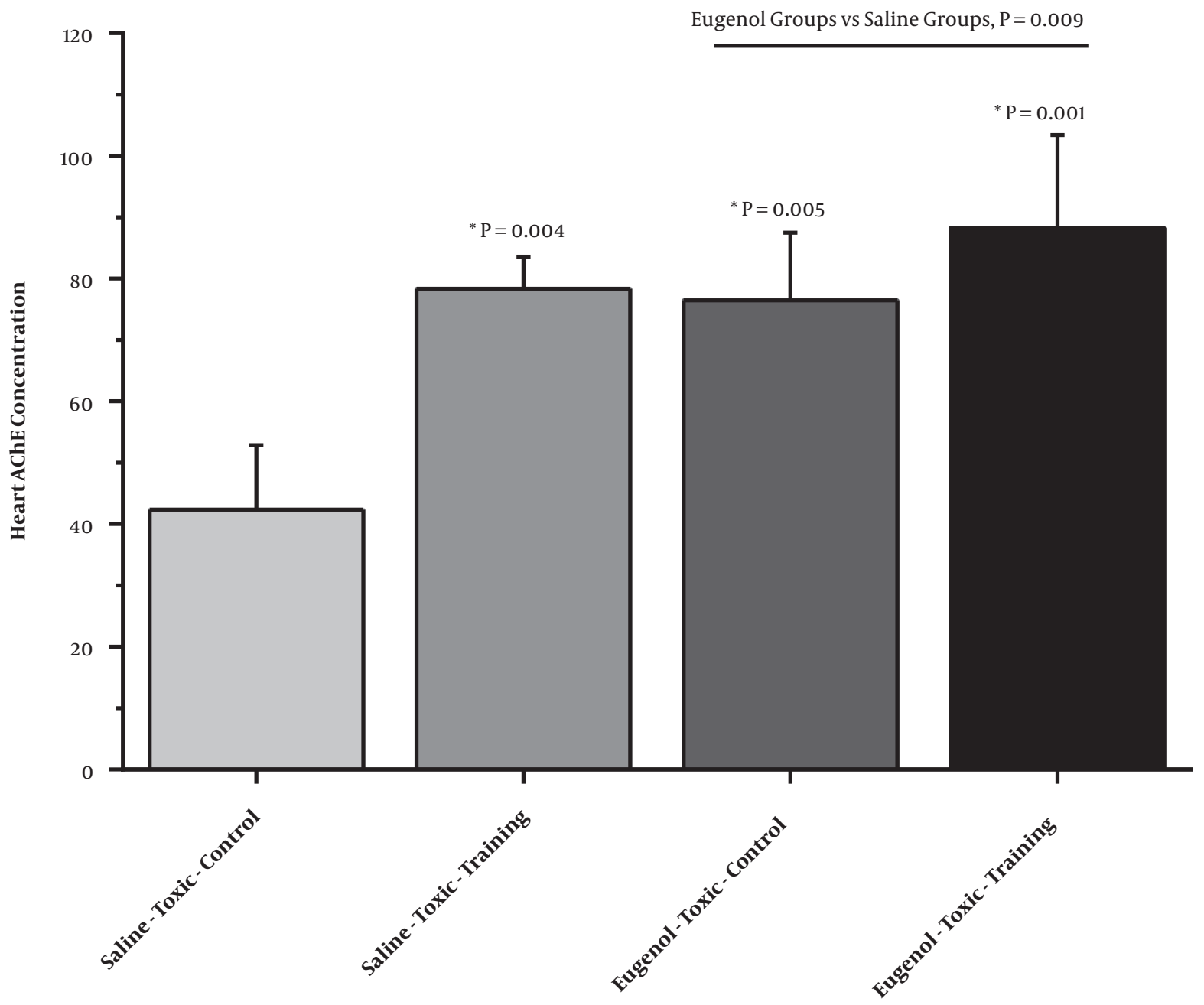

Figure 2. Cardiac acetylcholinesterase (AChE) $(\mathrm{ng} / \mathrm{mL})$ in saline-chlorpyrifos-control, saline-chlorpyrifos-training, eugenol-chlorpyrifos-control, and eugenol-chlorpyrifostraining groups. There were eight rats in each group. The data were expressed as means \pm standard deviation (SD) and analyzed using two-way ANOVA. *, A significant increase vs. the saline-chlorpyrifos-control group.

experiments, analyzed the data, wrote the first draft of the manuscript, and revised it. Both authors read and approved the final version of the manuscript.

Conflict of Interests: The authors declare that they have no conflict of interest.

Ethical Approval: The study was approved by the Islamic Azad University Ethics Committee (no.: 1012911712337521398162268642).

Funding/Support: Islamic Azad University (Central Tehran Branch, Iran) funded the project.

Informed Consent: None

\section{References}

1. Rahimi R, Nikfar S, Abdollahi M. Increased morbidity and mortality in acute human organophosphate-poisoned patients treated by oximes: a meta-analysis of clinical trials. Hum Exp Toxicol. 2006;25(3):157-62. doi: 10.1191/0960327106ht6020a. [PubMed: 16634335].

2. Kaur R, Sandhu HS. In vivo changes in antioxidant system and protective role of selenium in chlorpyrifos-induced subchronic toxicity in bubalus bubalis. Environ Toxicol Pharmacol. 2008;26(1):45-8. doi: 10.1016/j.etap.2008.01.004. [PubMed: 21783886].

3. Lataro RM, Silva CA, Fazan RJ, Rossi MA, Prado CM, Godinho RO, et al. Increase in parasympathetic tone by pyridostigmine prevents ventricular dysfunction during the onset of heart failure. 
Am J Physiol Regul Integr Comp Physiol. 2013;305(8):R908-16. doi: 10.1152/ajpregu.00102.2013. [PubMed: 23948774].

4. Behling A, Moraes RS, Rohde LE, Ferlin EL, Nobrega AC, Ribeiro JP. Cholinergic stimulation with pyridostigmine reduces ventricular arrhythmia and enhances heart rate variability in heart failure. Am Heart J. 2003;146(3):494-500. doi: 10.1016/S0002-8703(03)00319-3. [PubMed: 12947369].

5. Roy A, Guatimosim S, Prado VF, Gros R, Prado MA. Cholinergic activity as a new target in diseases of the heart. Mol Med. 2015;20:527-37. doi: 10.2119/molmed.2014.00125. [PubMed: 25222914]. [PubMed Central: PMC4365064].

6. Colovic MB, Krstic DZ, Lazarevic-Pasti TD, Bondzic AM, Vasic VM. Acetylcholinesterase inhibitors: pharmacology and toxicology. Curr Neuropharmacol. 2013;11(3):315-35. doi: 10.2174/1570159X11311030006. [PubMed: 24179466]. [PubMed Central: PMC3648782].

7. Rahmati-Ahmadabad S, Azarbayjani MA, Farzanegi P, Moradi L. Highintensity interval training has a greater effect on reverse cholesterol transport elements compared with moderate-intensity continuous training in obese male rats. Eur J Prev Cardiol. 2019:2047487319887830. doi: 10.1177/2047487319887828. [PubMed: 31718266].

8. Tian D, Meng J. Exercise for Prevention and Relief of Cardiovascular Disease: Prognoses, Mechanisms, and Approaches. Oxid Med Cell Longev. 2019;2019:3756750. doi: 10.1155/2019/3756750. [PubMed: 31093312]. [PubMed Central: PMC6481017].

9. Fouad AA, Yacoubi MT. Mechanisms underlying the protective effect of eugenol in rats with acute doxorubicin cardiotoxicity. Arch Pharm Res. 2011;34(5):821-8. doi: 10.1007/s12272-011-0516-2. [PubMed: 21656368].

10. Farzi MA, Sadigh-Eteghad S, Ebrahimi K, Talebi M. Exercise Improves Recognition Memory and Acetylcholinesterase Activity in the Beta Amyloid-Induced Rat Model of Alzheimer's Disease. Ann Neurosci. 2019;25(3):121-5. doi: 10.1159/000488580. [PubMed: 30814820]. [PubMed Central: PMC6388429].

11. Besnier F, Labrunee M, Pathak A, Pavy-Le Traon A, Gales C, Senard $\mathrm{JM}$, et al. Exercise training-induced modification in autonomic nervous system: An update for cardiac patients. Ann Phys Rehabil Med. 2017;60(1):27-35. doi:10.1016/j.rehab.2016.07.002. [PubMed: 27542313].

12. Dalai MK, Bhadra S, Chaudhary SK, Bandyopadhyay A, Mukherjee PK. Anti-cholinesterase activity of the standardized extract of Syzygium aromaticum L. Pharmacogn Mag. 2014;10(Suppl 2):S276-82. doi: 10.4103/0973-1296.133275. [PubMed: 24991103]. [PubMed Central: PMC4078338].

13. Binu P, Priya N, Abhilash S, Vineetha RC, Nair RH. Studies on curative efficacy of monoterpene eugenol on anti- leukemic drug arsenic trioxide induced cardiotoxicity. Biomed Pharmacother. 2017;91:559-66. doi:10.1016/j.biopha.2017.04.087. [PubMed: 28494415].

14. Nikbin S, Tajik A, Allahyari P, Matin G, Hoseini Roote SS, Barati E, et al. Aerobic exercise and eugenol supplementation ameliorated liver injury induced by chlorpyrifos via modulation acetylcholinesterase activation and antioxidant defense. Environ Toxicol. 2020;35(7):783-93. doi: 10.1002/tox.22913. [PubMed: 32096903]

15. Rompelberg CJ, Verhagen H, van Bladeren PJ. Effects of the naturally occurring alkenylbenzenes eugenol and trans-anethole on drug-metabolizing enzymes in the rat liver. Food Chem Toxicol. 1993;31(9):637-45. doi: 10.1016/0278-6915(93)90046-2. [PubMed:
8406240].

16. Khuanjing T, Palee S, Chattipakorn SC, Chattipakorn N. The effects of acetylcholinesterase inhibitors on the heart in acute myocardial infarction and heart failure: From cells to patient reports. Acta Physio (Oxf). 2020;228(2). e13396. doi:10.1111/apha.13396. [PubMed: 31595611].

17. Pope C, Karanth S, Liu J. Pharmacology and toxicology of cholinesterase inhibitors: uses and misuses of a common mechanism of action. Environ Toxicol Pharmacol. 2005;19(3):433-46. doi: 10.1016/j.etap.2004.12.048. [PubMed: 21783509].

18. Bittner EA, Martyn J. Neuromuscular Physiology and Pharmacology In: Hemmings HC, Egan TD, editors. Pharmacology and Physiology for Anesthesia. 2nd ed. Philadelphia: Elsevier; 2019. p. 412-27. doi: 10.1016/b978-0-323-48110-6.00021-1.

19. Duysen EG, Stribley JA, Fry DL, Hinrichs SH, Lockridge O. Rescue of the acetylcholinesterase knockout mouse by feeding a liquid diet; phenotype of the adult acetylcholinesterase deficient mouse. Brain Res Dev Brain Res. 2002;137(1):43-54. doi: 10.1016/s0165-3806(02)00367-x. [PubMed: 12128253].

20. Vignaud A, Fougerousse F, Mouisel E, Guerchet N, Hourde C, Bacou F, et al. Genetic inactivation of acetylcholinesterase causes functional and structural impairment of mouse soleus muscles. Cell Tissue Res. 2008;333(2):289-96. doi: 10.1007/s00441-008-0640-6. [PubMed: 18560895].

21. Xie W, Stribley JA, Chatonnet A, Wilder PJ, Rizzino A, McComb RD, et al Postnatal developmental delay and supersensitivity to organophosphate in gene-targeted mice lacking acetylcholinesterase.JPharmacol Exp Ther. 2000;293(3):896-902. [PubMed: 10869390].

22. Mouisel E, Blondet B, Escourrou P, Chatonnet A, Molgo J, Ferry A. Outcome of acetylcholinesterase deficiency for neuromuscular functioning. Neurosci Res. 2006;55(4):389-96. doi: 10.1016/j.neures.2006.05.002. [PubMed: 16766072].

23. Ohno K, Engel AG, Brengman JM, Shen XM, Heidenreich F, Vincent A, et al. The spectrum of mutations causing end-plate acetylcholinesterase deficiency. Ann Neurol. 2000;47(2):162-70. [PubMed: 10665486].

24. Garcia CC, Potian JG, Hognason K, Thyagarajan B, Sultatos LG, Souayah $\mathrm{N}$, et al. Acetylcholinesterase deficiency contributes to neuromuscular junction dysfunction in type 1 diabetic neuropathy. Am JPhysiol Endocrinol Metab. 2012;303(4):E551-61. doi: 10.1152/ajpendo.00622.2011. [PubMed: 22739110]. [PubMed Central: PMC3423102].

25. Chau DT, Rada P, Kosloff RA, Taylor JL, Hoebel BG. Nucleus accumbens muscarinic receptors in the control of behavioral depression: antidepressant-like effects of local M1 antagonist in the Porsolt swim test. Neuroscience. 2001;104(3):791-8. doi: 10.1016/s03064522(01)00133-6. [PubMed: 11440810].

26. Wen G, Hui W, Dan C, Xiao-Qiong W, Jian-Bin T, Chang-Qi L, et al. The effects of exercise-induced fatigue on acetylcholinesterase expression and activity at rat neuromuscular junctions. Acta His tochem Cytochem. 2009;42(5):137-42. doi: 10.1267/ahc.09019. [PubMed: 19918322]. [PubMed Central: PMC2775104].

27. Vieira JM, Gutierres JM, Carvalho FB, Stefanello N, Oliveira L, Cardoso AM, et al. Caffeine and high intensity exercise: Impact on purinergic and cholinergic signalling in lymphocytes and on cytokine levels. Biomed Pharmacother. 2018;108:1731-8. doi: 10.1016/j.biopha.2018.10.006. [PubMed: 30372876]. 